Article

\title{
Evaluation of Ecological Stability in Semi-Arid Open-Pit Coal Mining Area Based on Structure and Function Coupling during 2002-2017
}

\author{
Xinhui Li ${ }^{1,2} \oplus$, Shaogang Lei ${ }^{2,3}, *$, Ying Liu ${ }^{4} \oplus$, Hang Chen ${ }^{5}{ }^{\oplus}$, Yibo Zhao ${ }^{2}$, Chuangang Gong ${ }^{2} \oplus$, Zhengfu Bian ${ }^{2}$ \\ and Xiaoguang $\mathrm{Lu}^{3}$
}

check for

updates

Citation: Li, X.; Lei, S.; Liu, Y.; Chen, H.; Zhao, Y.; Gong, C.; Bian, Z.; Lu, X. Evaluation of Ecological Stability in Semi-Arid Open-Pit Coal Mining Area Based on Structure and Function Coupling during 2002-2017. Remote Sens. 2021, 13, 5040. https://doi.org/ $10.3390 /$ rs13245040

Received: 17 October 2021

Accepted: 9 December 2021

Published: 11 December 2021

Publisher's Note: MDPI stays neutral with regard to jurisdictional claims in published maps and institutional affiliations.

Copyright: (c) 2021 by the authors. Licensee MDPI, Basel, Switzerland. This article is an open access article distributed under the terms and conditions of the Creative Commons Attribution (CC BY) license (https:/ / creativecommons.org/licenses/by/ $4.0 /)$.
1 School of Public Policy \& Management (School of Emergency Management), China University of Mining and Technology, Xuzhou 221116, China; xinhui.li@cumt.edu.cn

2 Engineering Research Center of Ministry of Education for Mine Ecological Restoration, China University of Mining and Technology, Xuzhou 221116, China; TB19160018B2@cumt.edu.cn (Y.Z.); chggong@cumt.edu.cn (C.G.); zfbian@cumt.edu.cn (Z.B.)

3 Engineering Research Center for Coal Mining Subsided Land and Goaf Treatment of Shandong, Jining 272100, China; ts16160127a3@cumt.edu.cn

4 School of Earth and Environment, Anhui University of Science and Technology, Huainan 232001, China; liuying340825@cumt.edu.cn

5 Department of Land Management, School of Public Affairs, Zhejiang University, Hangzhou 310058, China; c.hang@zju.edu.cn

* Correspondence: lsgang@cumt.edu.cn

\begin{abstract}
Open-pit coal mining plays an important role in supporting national economic development; however, it has caused ecological problems and even seriously impacted regional ecological stability. Given the importance of maintaining ecological stability in semi-arid coal mining areas, this study used a coupling coordination degree approach based on the structural and functional state transition model (SFSTM) to evaluate the spatio-temporal variation of ecological stability from 2002 to 2017 by using MODIS and Landsat datasets in the semi-arid open-pit coal mining area. Besides, random points were created for different ecological stability levels (containing natural areas, coal mining areas, and reclamation areas) and segment linear regression was conducted to determine the structural change threshold for negative state transitions based on mining and positive state transitions based on reclamation. Furthermore, the impact factors of ecological stability were analyzed. Results showed that ecological stability fluctuated significantly over 16 years, showing a trend of first increasing and then decreasing. It was found that precipitation and temperature were the key natural factors affecting ecological stability, and mining activities constituted the dominant factor. The average perturbation distances to ecological stability from mining activities in the west, southwest, and east mining groups were 7500, 5500, and $8000 \mathrm{~m}$, respectively. SFSTM is appliable to the coal mining ecosystem. Quantitative models of ecological stability response can help resolve ambiguity about management efficacy and the ecological stability results facilitate iterative updating of knowledge by using monitoring data from coal mining areas. Moreover, the proposed ecological structural threshold provides a useful early warning tool, which can aid in the reduction of ecosystem uncertainty and avoid reverse transformations of the positive state in the coal mining areas.
\end{abstract}

Keywords: open-pit coal mines; ecological stability; structural variables; functional variables; structural and functional state transition model

\section{Introduction}

Considering rapid mining scale expansion and its environmental impact, environmental management after mining has become particularly important [1]. The main objective of environmental management is to preserve ecological stability while conserving capacity to respond and adapt to disturbances and/or future changes and maintaining ecological 
function [2]. It is necessary to establish standards to guide environmental management in post-mining areas. A mining area, which constitutes a dynamic system, is an important part of an ecosystem. In other words, the composition of a mining system interacts with the surrounding environment and is in a dynamic equilibrium state [3]. Coal mine exploitation of has caused a series of environmental problems, such as vegetation degradation [4], soil erosion [5], heavy metal pollution [6], ground subsidence [7], degradation of natural resources, and also threat to biodiversity, which can further change ecological structure and function, eventually affecting ecological stability in the coal mining area. Therefore, ecological stability was selected as an index to measure the state of the system, and ecological stability evaluation became the standard for environmental management after mining.

The concept of ecological stability originates from that of community stability [8]. Ecological stability is commonly defined as the ability of an ecosystem to resist changes despite perturbations and its resilience after disturbance [9]. Once resilience and resistance have been altered, ecosystem structure and function change correspondingly [10]. According to the general concept of ecological stability, the stability of a mining area ecosystem is defined as an appropriate ecological structure with a higher ecological function made up of regional key ecological elements and their environments. Notably, it is determined under the condition of dynamic adaptation and co-evolution after coal mining and other disturbances at a specific space-time scale, ultimately ensuring the sustainable development of coal mining and the environment. To measure ecological stability, some scholars have derived mathematical and physical methods to simulate changes in dynamic ecosystems [11,12] and used mathematical analyses or computer numerical simulations to analyze the stability of multi-species communities. Nevertheless, the prediction of ecological stability by using mathematical methods is mostly theoretical. Yue and Ma introduced the theory of thermodynamic stability into the ecosystem, determined a corresponding entropy function to judge the degree of stability, and revealed the degree of system stability but ignored the difference of spatial stability [13]. Li et al. [9] studied the ecological stability of dumps in a mining area by obtaining vegetation and soil factors based on the coupling coordination degree model. A coupling coordination model refers to the concept of capacitive coupling and a corresponding coefficient model in physics [14]. In physics, coupling is a phenomenon in which two (or more) systems or system elements interact with each other in various ways. Coordination is a benign correlation between two or more systems or elements, and it is the guarantee of the stable development of multiple systems or elements $[15,16]$. When a system or its internal elements cooperate properly and complement each other, it results in benign coupling, or a stable ecosystem; otherwise, there is malignant coupling, leading to an unstable ecosystem. In the light of this definition, a mining ecosystem is composed of structural and functional elements. Therefore, the coupling coordination degree model can be introduced into ecosystem stability measurements and the ecological stability index is represented based on the study by Li et al. [9]. However, the coupling coordination degree model cannot reflect the dynamic conversion process of ecological structure, function and ecological stability during coal mining, and can only reflect ecological stability results. Herein, the structure-function state transition model was introduced.

The State and Transition Model (STM), first proposed in 1989 and used in pasture management, was designed to provide a conceptual framework that represented the response of pasture ecosystems to natural or management-induced interference [17-20]. Based on an STM conceptual model, López et al. [10] proposed a structural and functional state transition model (SFSTM) as a conceptual framework to evaluate the related attributes of ecosystem elasticity, such as elasticity, amplitude, and stability. Notably, STM and SFSTM were mainly used to evaluate alternative conversion scenarios in arid and semiarid areas and improve our understanding of vegetation dynamics or design on-site prevention and control measures [21-23]. López et al. [10] optimized the STM model by proposing the following two principal axes: (a) the x-axis determined by structural ecosystem changes and (b) the y axis determined by ecosystem functions and/or processes (Figure 1). The use of the axis is based on the assumption that excessive disturbance 
negatively impacts the ecosystem's composition, structure, and function [10,24]. They believed that every alternative ecosystem state could be subjected to different levels of dynamic change, such as stability, instability, sub-stability, and so on [2]. Each state has different structural-functional feedback characteristics. In a mining ecosystem, natural disturbance events (e.g., droughts, fire) or human disturbance (e.g., mining, restoration) can shift the ecosystem stability state, triggering a transition to other states (positive or negative) [25]. Therefore, the dynamic process of coal mining can be determined by establishing the correlation between structural degradation indicators and functions, and the mutation point of the function slope can be regarded as the key point (range) of ecological state transition, indicating the change in the ecological stability Furthermore, López et al. [2] set up field tests for structural and functional indices in different vegetation community states, and established a relationship among vegetation structure, functional index, and ecological stability while dealing with interference. Cavallero et al. [25] studied the structural and functional variables of forest systems affected by fire and found them to be nonlinear. Peri et al. [26] determined the key thresholds for transitions between different states of a forest system by constructing a segmented regression of structural degradation and functional indices.

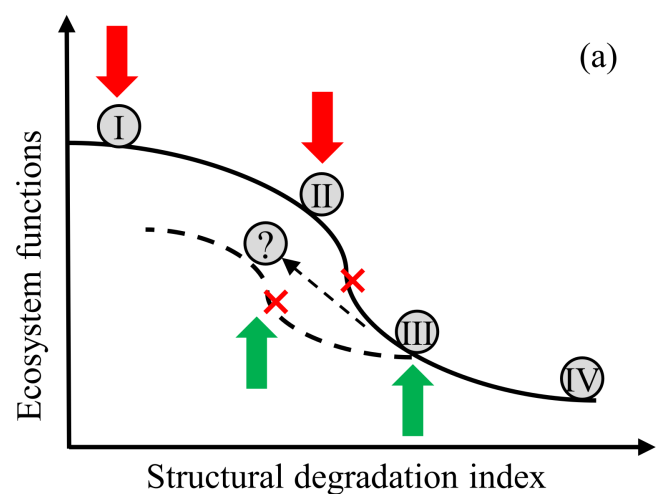

Structural degradation index

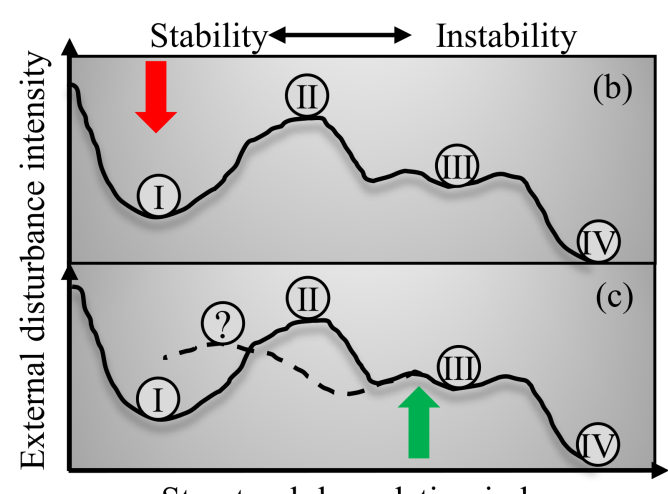

Structural degradation index

Figure 1. Schematic representation of the stability of different states in a coal mining ecosystem, based on: (a) the Structural-Functional State and Transition Model, modified from reference [10]; $(\mathbf{b}, \mathbf{c})$ the cup ball model. Gray balls with symbols I, II, III and IV represent different states, and ecological stability decreases successively from I to IV. The red arrows represent negative disturbance factors (e.g., coal mining activities), the green arrows represent positive disturbance factors (e.g., vegetable restoration). The gray ball with the (?) symbol represents the state in which it triggers a positive transition (dashed arrow) from an unstable dynamic equilibrium state, when coal mining is removed. The red cross represents the key point of ecological state transition.

However, the existing research is based on continuous field monitoring, which is both time-consuming and laborious. Mining areas are large and unfortunately, field studies cannot cover them all. Therefore, herein, a convenient and fast method was selected to obtain structural and functional indicators over large coal mining areas using remote sensing images. Earlier studies of remote sensing applications for coal mining mainly focused on monitoring the expansion of coal activities [27] and the change of landscape pattern [28], exploring the change trend of ecological environments, such as vegetation index [4], soil moisture content [29], groundwater [30], carrying out vegetation classification [31], developing ecological evaluation, such as ecological health evaluation [32] and ecological vulnerability assessment [33]. However, few studies have focused on evaluating the changes of ecological stability in open-pit coal mine areas, it is meaningful and necessary to study the change trend of ecological stability in open-pit mining areas by means of remote sensing. The Jungar Banner open-pit coal mining area is located in the semiarid region of western China, and the ecological stability of the mining area has changed significantly under the mining disturbance. By using the time series remote sensing data of ecological structural and functional indicators from 2002 to 2017, the main objective of 
this study was to explore the spatio-temporal dynamics of ecological stability in the coal mining area based on the coupling coordination degree model. Moreover, random samples under different ecological states were selected and the structural or functional change threshold under different state transitions was evaluated based on the SFSTM conceptual framework to guide ecological restoration in the mining area.

\section{Materials and Methods}

\subsection{Study Area}

The study area is approximately $7.55 \times 10^{3} \mathrm{~km}^{2}$; it is located in Jungar Banner $\left(39^{\circ} 16^{\prime}-\right.$ $40^{\circ} 20^{\prime}$ north (N), $110^{\circ} 05^{\prime}-111^{\circ} 27^{\prime}$ east (E); $1100-1250 \mathrm{~m}$ above sea level (a.s.l.)), in the eastern part of China's Inner Mongolia Autonomous Region. Digital Elevation Model (DEM) data were derived from the Geographical Information Monitoring Cloud Platform (http: / / www.dsac.cn / accessed on 1 June 2018). The topography is high in the northwest and low in the southeast. The main elevation features include arsenic sandstone, aeolian sand, and loess gullies. The boundary of mineral resources was provided by the Environmental Restoration and Management Center of the Jungar Banner mining area. Mineral resources of Jungar Banner are distributed in the western, southwestern, and eastern parts (Figure 2), with barren land and a fragile environment. The study area is characterized by a semi-arid climate with uneven precipitation distribution that is mainly concentrated in the summer. The average annual precipitation is $408 \mathrm{~mm}$, while the average annual evaporation capacity is about $2100 \mathrm{~mm}$. The annual average temperature is $7.2^{\circ} \mathrm{C}$. The Yellow River is the largest surface water body in Jungar Banner. It is not only a regional discharge channel for surface water and groundwater but also supplies groundwater in this area. The region is a nationally comprehensive energy base, characterized by high-intensity, large-scale coal exploitation.

\section{Legend}

The people of Republic of China

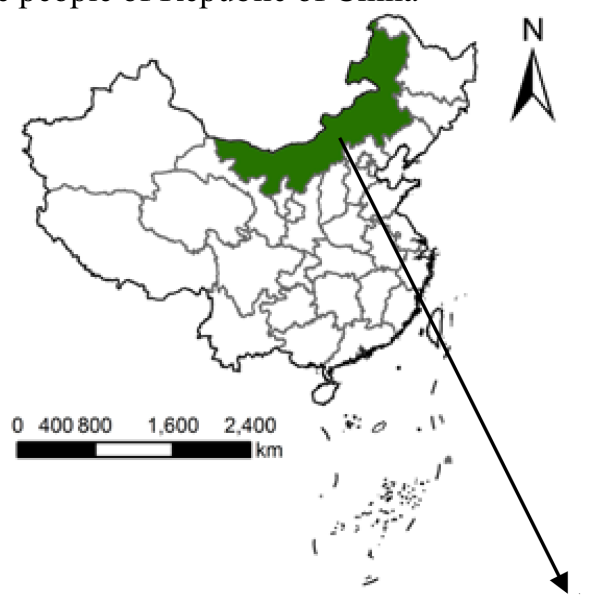

Inner Mongolia

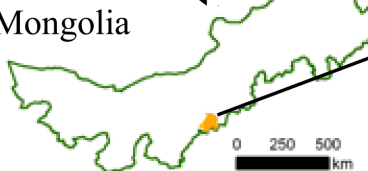

Coal mining boundary Western coal mine group Southwest coal mine group Eastern coal mine group DEM High:1588
Low:816

\author{
p
}

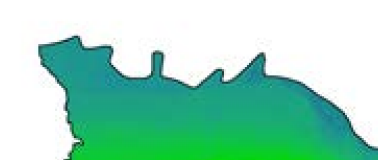

.
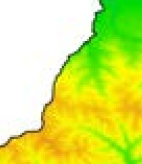

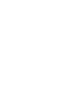


is a key feature in a mining system and can alter regional patterns, reduce vegetation coverage, change patch connectivity, and accelerate regional fragmentation. Therefore, in mining ecosystems, structural variables used to characterize changes in ecological stability response are based on vegetation composition and overall landscape pattern. For ecological structural variables, with the exception of the vegetation composition index, it was, therefore, necessary to obtain the cohesion index $(\mathrm{COH})$, division index (DIV) and Shannon index (SHDI) at the landscape level of a coal mining ecosystem after human interference.

The COH, DIV, and SHDI indexes were obtained by using the Fragstats 4.2 mobile window method [32]. These indices were estimated based on Landsat images over the study area. Affected by cloud cover, six Landsat images (2002a, 2005a, 2008a, 2011a, 2014a, 2017a) were selected (downloaded from https: / / glovis.usgs.gov / accessed on 1 June 2018) and divided into seven categories by using the software ENVI 5.2. The structural scattering index (SSI) was selected based on MODIS BRDF 43A1 images with a spatial resolution of $500 \mathrm{~m}$ and a temporal resolution of $16 \mathrm{~d}$ (downloaded from https: / / lpdaac.usgs.gov / products/mcd43a1v006/ accessed on 8 June 2019) to represent vegetation composition. The index is represented as follows:

$$
S S I=\ln \left(f_{\text {vol }}^{\text {nir }} / f_{g e o}^{r e d}\right)
$$

where $f_{\text {vol }}^{\text {nir }}$ represents the weight of volume scattering in the near-infrared band, and $f_{\text {geo }}^{\text {red }}$ represents the weight of geometric scattering in the near-infrared band. Owing to the high transmittance of vegetation to the near-infrared band, canopy multiple scattering reduces reflection anisotropy, which can be expressed in terms of the volume scattering nucleus in the near-infrared band. In contrast, vegetation chlorophyll absorbs a large amount of red light band and enhances reflection anisotropy, which can be expressed by the geometric scattering nucleus of the red light band. Dense and flat vegetation has higher volume scattering, while sparse and undulating vegetation has higher geometric scattering. Previous studies have shown that this index can reflect sparse herbaceous vegetation, shrubs, and crops (such as corn and soybeans) with a lower structural scattering index, while dense woodlands have a higher structural scattering index [36,37].

Regarding the ecological functional variables, the main focus was on the ecological service functions (ESF) provided by open-pit mining areas to humans, including supply, regulation, support and cultural services. In this study, ESF in the Jungar Banner openpit coal mines was calculated according to the method reported in Xie's study [38]. The ecosystem services coefficients for each land use type referred to ratios between the values of the average ecosystem services of different ecosystem types calculated by Wu et al. [32]. In this study, the ESF coefficients were preliminarily determined for different land use types in the Jungar Banner open-pit coal base, ranging from 0 to 1: forest land 0.474, grassland 0.157 , cultivated land 0.150 , water area 1 , unused land 0.09 , construction 0 , and mining 0 . The ESF is represented as follows [39]:

$$
E S F=\sum_{i=1}^{\mathrm{n}}\left(P_{i} \times A_{i}\right)
$$

where $P_{i}$ indicates the total value of the ESF per unit area of the $i$-th land use type; $A_{i}$ indicates the area of land use type $i$ in the study area.

At the same time, herein, the soil erosion index (RUSLE) and gross primary productivity (GPP) were selected considering the key role vegetated systems play during mining ecological activities. The growth status and structure of vegetation affect regional soil erosion, an important indicator of soil conservation that was estimated according to Zhuang's research [40].GPP is an important index to characterize ecosystem carbon cycles and vegetation ecological activities [41]. It was calculated by using MODIS 17A2H data with a spatial resolution of $500 \mathrm{~m}$ and a temporal resolution of $16 \mathrm{~d}$ (downloaded from https: / /lpdaac.usgs.gov / products / mod17a2hv006/ accessed on 8 June 2019) [42] (Table 1). The processing steps of MODIS datasets referred to Li's research [4]. The Landsat datasets were resampled to $500 \mathrm{~m}$ to match the resolution of the MODIS datasets. 
Table 1. Structural and functional variables used for ecological stability in the coal mining area.

\begin{tabular}{|c|c|c|c|}
\hline Characteristic & Variables & Data & Implication \\
\hline \multirow{3}{*}{ Structure } & $\begin{array}{l}\text { Structural scattering index } \\
\text { (SSI) }\end{array}$ & $\begin{array}{c}\text { MODIS BRDF 43A1 } \\
(2002 / 2005 / 208 / 2011 / 2014 / 2017)\end{array}$ & $\begin{array}{l}\text { Reflects the growth status and composition } \\
\text { of vegetation communities through the } \\
\text { three-dimensional structure of the canopy }\end{array}$ \\
\hline & $\begin{array}{c}\text { Division } \\
\text { Index (DIV) }\end{array}$ & $\begin{array}{c}\text { Landsat TM/OLI } \\
(2002 / 2005 / 2008 / 2011 / 2014 / 2017)\end{array}$ & $\begin{array}{l}\text { The degree of separation of individual } \\
\text { distribution of different patch numbers in a } \\
\text { certain landscape type, the greater the degree } \\
\text { of separation, the higher the index }\end{array}$ \\
\hline & Shannon index (SHDI) & $\begin{array}{c}\text { Landsat TM/OLI } \\
(2002 / 2005 / 2008 / 2011 / 2014 / 2017)\end{array}$ & $\begin{array}{l}\text { Reflects the heterogeneity of the landscape, } \\
\text { that is, the complexity of the spatial structure } \\
\text { of the landscape. The greater the } \\
\text { heterogeneity, the lower the degree of order }\end{array}$ \\
\hline \multirow{4}{*}{ Function } & Cohesion index $(\mathrm{COH})$ & $\begin{array}{c}\text { Landsat TM/OLI } \\
(2002 / 2005 / 2008 / 2011 / 2014 / 2017)\end{array}$ & $\begin{array}{l}\text { Reflects the aggregation and dispersion of } \\
\text { patches in the landscape, the greater the } \\
\text { degree of connection, the higher the index }\end{array}$ \\
\hline & Ecosystem service (ESF) & $\begin{array}{c}\text { Landsat TM/OLI } \\
(2002 / 2005 / 2008 / 2011 / 2014 / 2017)\end{array}$ & $\begin{array}{l}\text { Static indicator, include supply, regulation, } \\
\text { support and cultural service. }\end{array}$ \\
\hline & Soil erosion (RUSLE) & $\begin{array}{c}\text { Landsat TM/OLI } \\
(2002 / 2005 / 2008 / 2011 / 2014 / 2017)\end{array}$ & Dynamic indicator, represents the key role of \\
\hline & $\begin{array}{l}\text { Gross primary productivity } \\
\text { (GPP) }\end{array}$ & $\begin{array}{c}\text { MODIS 17A2H } \\
(2002 / 2005 / 2008 / 2011 / 2014 / 2017)\end{array}$ & $\begin{array}{l}\text { vegetation elements in the process of } \\
\text { ecological activities in the mining area. }\end{array}$ \\
\hline
\end{tabular}

To analyze the correlation between NDVI and ecological stability, we downloaded the MODIS-NDVI 13Q1 with a spatial resolution of $500 \mathrm{~m}$ and a temporal resolution of $16 \mathrm{~d}$ from the National Aeronautics and Space Administration (NASA) Earth Observation System (EOS) (http:/ / reverb.echo.nasa.gov / reverb / accessed on 1 June 2018) [4]. In this study, meteorological data from 2002 to 2017 were collected from the meteorological station located in the Jungar Banner mining area and the correlation between ecological stability and annual average precipitation and temperature was analyzed. Besides, to analyze the impact of mining activities on ecological stability, a buffer zone analysis was used to reflect the change of ecological stability with distance from the mining area. The coal mining boundary of each mine group was used as the buffer origin, and the buffer analysis tool in ArcGIS 10.2 software was used to prepare a buffer with a sampling interval of $500 \mathrm{~m}$ and a sampling range of 500-10,000 m. We used mask technology to exclude the influence of the construction land on the results.

\subsection{Methods}

\subsubsection{Ecological Stability Evaluation}

Ecological stability in the semi-arid open-pit coal mine area was calculated by a coupling coordination degree model using Equations (3)-(5) $[4,16]$. Spatial distribution maps of ecological stability associated with different grades from 2002 to 2017 in the case study area were generated by using ArcGIS 10.2. The natural breakpoint method was used to classify the ecological stability of the study area into the following five levels: Extremely stable (S-I); stable (S-II); sub-stable (S-III); unstable (S-IV); and extremely unstable (S-V) (Table 2):

$$
\begin{gathered}
\mathrm{ES}=\sqrt{\mathrm{C} \times \mathrm{T}} \\
\mathrm{C}=\sqrt{\frac{(f(\mathrm{x}) \times f(\mathrm{y}))}{\left(\frac{f(\mathrm{x})+f(\mathrm{y})}{2}\right)^{2}}} \\
\mathrm{~T}=\alpha f(\mathrm{x})+\beta f(\mathrm{y})
\end{gathered}
$$

where $f(\mathrm{x})$ is the structural comprehensive index, $f(\mathrm{y})$ is the functional comprehensive index, and the weight of each index was determined by the entropy weight method. ES is the ecological stability of the mining area system, and $C$ is the coupled structural 
comprehensive index and a functional comprehensive index, reflecting system structure and function interactions; T denotes the overall development level of the system, and $\alpha$ and $\beta$ are the respective contributions of the structural and functional comprehensive index. As they are equally important to ES, both $\alpha$ and $\beta$ were set as 0.5 . The ES value was set in the range of $0-1$, with a higher value indicating a higher regional ES, and vice versa.

Table 2. Classification of ecological stability in the coal mining area.

\begin{tabular}{cc}
\hline Category & Description \\
\hline Extremely stable & Natural areas, basically unmanned disturbance \\
Stable & Natural areas, but with little human disturbance, \\
& Reclamation areas, with a longer reclamation period \\
Natural areas, but with higher human disturbance, & Reclamation areas, with shorter reclamation period; \\
Newly reclaimed areas, & Newle \\
Unstable & Non-reclaimed areas, artificial areas (farmland, orchard, etc.) \\
Extremely unstable & Coal mine areas, Cities, Desert \\
\hline
\end{tabular}

\subsubsection{Ecological Structure and Function Correlation under the SFSTM}

In order to verify that the SFSTM was applicable to the mining area ecosystem, herein random points in the open-pit areas (extremely unstable: $\mathrm{S}-\mathrm{V}_{\mathrm{m}}$ ), reclamation areas (unstable: S-IV $\mathrm{V}_{\mathrm{r}}$ ), reclamation areas (sub-unstable: $\mathrm{S}-\mathrm{III}_{\mathrm{r}}$ ), reclamation areas (stable: $\mathrm{S}-\mathrm{II}_{\mathrm{r}}$ ) and natural areas (extremely stable: $S-I_{n}$ ) of the western, southwest, and eastern mining groups were established based on the special environment of Jungar Banner (Figure 3). Considering the natural area as a reference control area, a matrix containing all the structural variables was used, and the Mahalanobis distance (MD) between random points in the different areas (state and/or phase) was calculated in this study [26]. Then, the structural degradation index (SDI) was adapted as follows: $\mathrm{SDI}_{i}=\mathrm{MD}_{i} * 100 / \mathrm{MD}_{\max }$, where $\mathrm{MD}_{i}$ is the $\mathrm{MD}$ between the $\mathrm{i}$-th point and a reference point. $\mathrm{MD}_{\max }$ corresponds to a maximum MD value in all points. All MD values were standardized based on the $\mathrm{MD}_{\max }$, which determined that SDI varied between 0 and $100 \%$. Then regressions of the functional comprehensive index $(\mathrm{F})$ of random points in relation to the SDI were adjusted to segmented linear regressions ( $p$ values $\leq 0.05$ ). The adjusted regressions included: (1) negative state transitions: $\mathrm{S}-\mathrm{I}_{\mathrm{n}}$ and $\mathrm{S}-\mathrm{V}_{\mathrm{m}}$; (2) positive state transitions: $\mathrm{S}-\mathrm{V}_{\mathrm{m}}, \mathrm{S}-\mathrm{IV}_{\mathrm{r}}, \mathrm{S}-\mathrm{III}_{\mathrm{r}}$, and S- $\mathrm{II}_{\mathrm{r}}$ (Figure 4). Piecewise regression is an effective tool to determine the threshold of mutations between different states. Herein, SDI was used as an explanatory variable and functional comprehensive index $(\mathrm{F})$ as a response variable to determine structural indication thresholds among different states.

\subsubsection{Pearson Correlation Analysis}

To analyze the impact of natural factors and NDVI on variations in ecological stability, we calculated the correlation coefficient (CC) between the ecological stability with them. Its value ranges from -1 to 1 . A positive value indicates a positive correlation and a negative value indicates a negative correlation. The formula is as follows:

$$
r=\frac{\sum_{j=1}^{n}\left(x_{j}-\bar{x}\right)\left(y_{j}-\bar{y}\right)}{\sqrt{\sum_{j=1}^{n}\left(x_{j}-\bar{x}\right)^{2}} \sqrt{\sum_{j=1}^{n}\left(y_{j}-\bar{y}\right)^{2}}}
$$

where $x_{j}$ is the annual influencing factor, $\bar{x}$ is the average value of the influencing factor, $\mathrm{y}_{\mathrm{j}}$ is the annual ES, $\overline{\mathrm{y}}$ is the average value of $\mathrm{ES}$, and $n$ is the sample number. It is generally considered that the weak correlation is $0 \leq|\mathrm{r}| \leq 0.30$, the low correlation is $0.30<|\mathrm{r}| \leq 0.50$, the strong correlation is $0.50<|\mathrm{r}| \leq 0.80$, and $0.80<|\mathrm{r}|<1$ is very high correlation. Additionally, a t-test was conducted to test the significance of the value of $r$. 


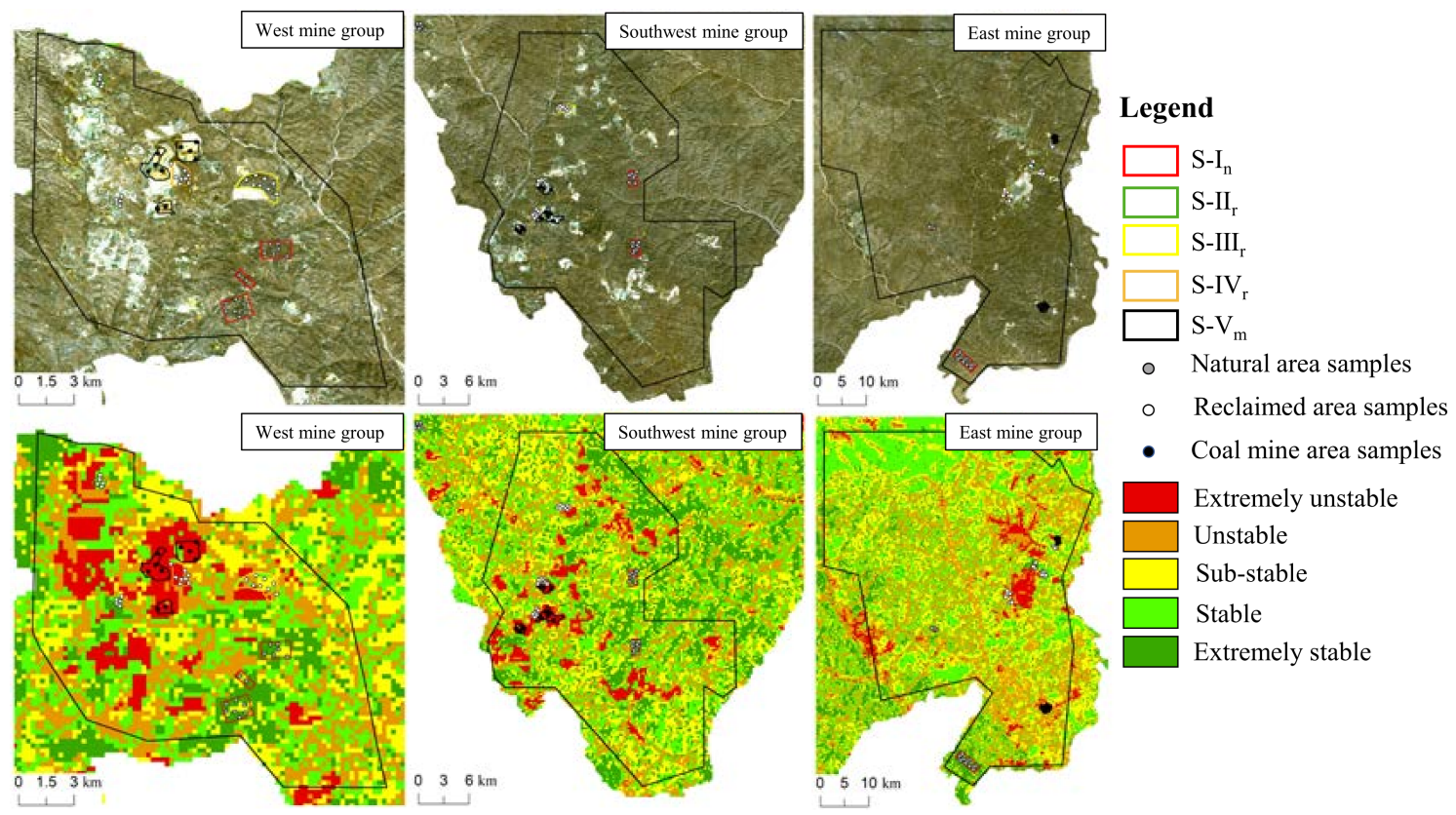

Figure 3. Schematic illustration of sampling points in each coal mining area based on ecological stability in 2017.

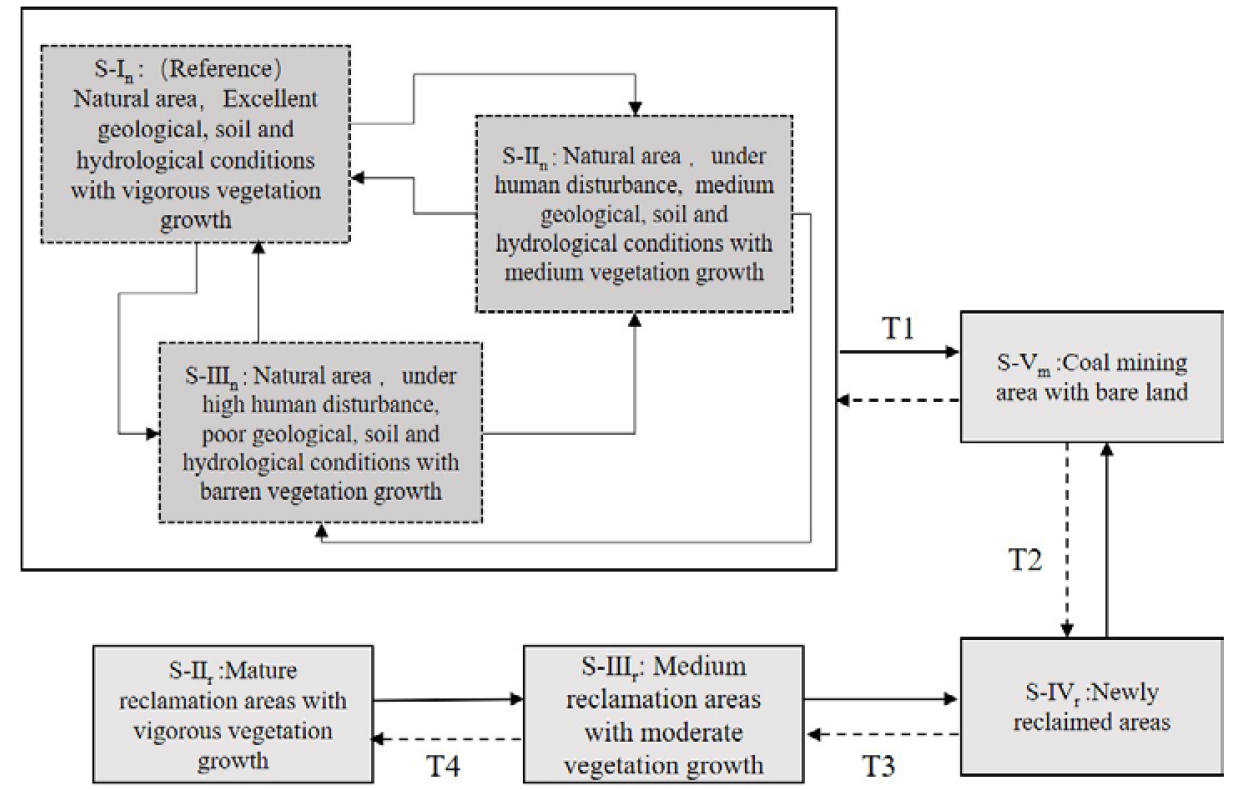

Figure 4. Conceptual state and transition model for Jungar Banner coal mining ecosystems based on the random points method. The gray boxes represent states (Roman numerals), the subscript $\mathrm{n}$ represents natural areas, the subscript $r$ represents reclaimed areas, and the subscript $m$ represents mining areas. The dotted line boxes are phases within the same state and the black polyline arrows represent reversible pathways between phases. The black solid straight arrows represent negative transitions between states (negative disturbance, e.g., mining activities or drought), and the black dashed straight arrows represent positive transitions (vegetation restoration) (labeled in letter T with Arabic numerals, which refer to state transition thresholds).

\section{Results}

\subsection{Ecological Stability Spatio-Temporal Change}

Stable and extremely stable regions were mainly distributed in the middle and southeast corner of Jungar Banner, while the unstable and extremely unstable regions were 
mainly distributed around mining and towns (Figure 5). From 2002 to 2017, the average ecological stability of Jungar Banner was 0.618, 0.671, 0.702, 0.672, 0.625, and 0.622, respectively, showing a fluctuating trend, and more than $50 \%$ of areas were above the sub stable state. By comparing changes in ecological stability level of the five phases from 2002 to 2017 (Figure 6), extremely unstable areas increased by $67.01 \%$ in 2017 compared to that in 2002. The unstable and sub-stable areas decreased by 14.16 and $14.83 \%$, respectively, in 2017 compared to that in 2002. However, a slight rebound with a slow downward trend was observed after 2008. The stable and extremely stable areas overall increased by 12.14 and $30.17 \%$, respectively, in 2017 compared to that in 2002.

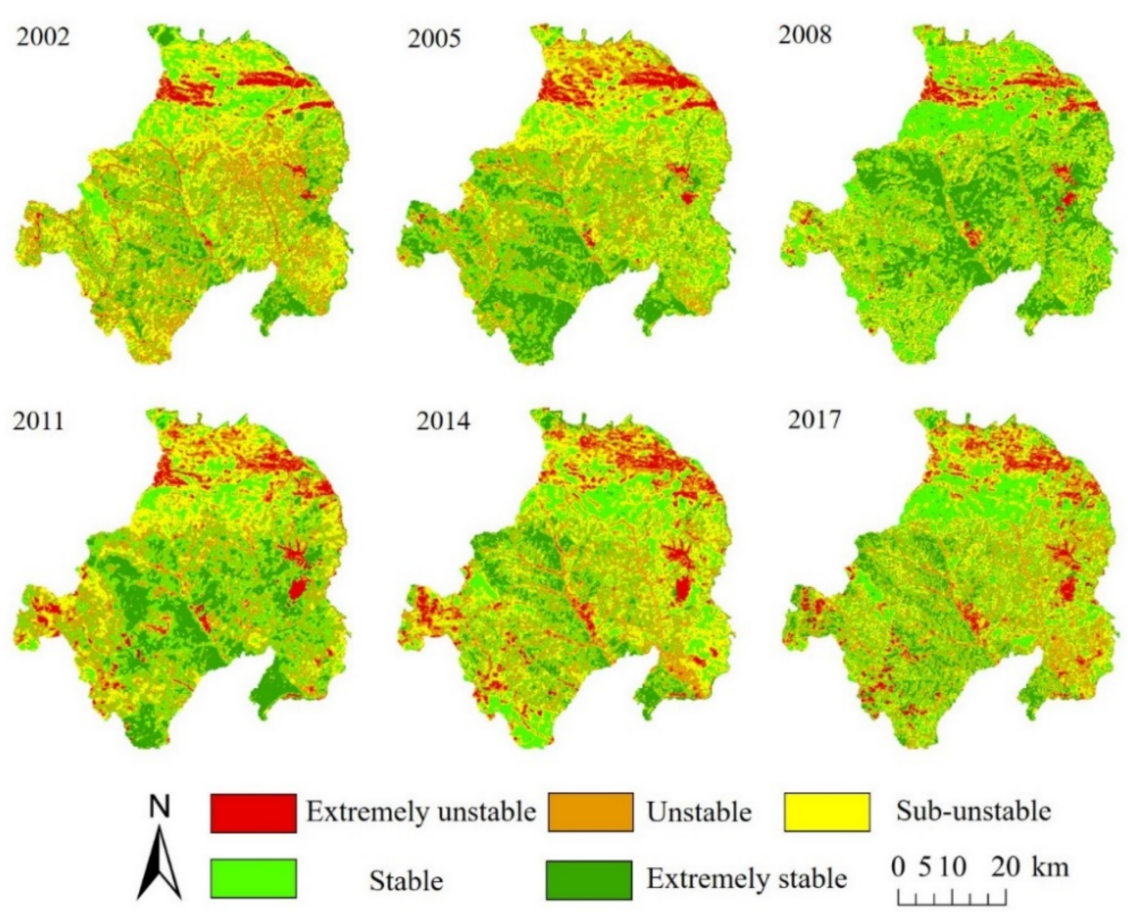

Figure 5. The spatial distributions of ecological stability from 2002 to 2017.

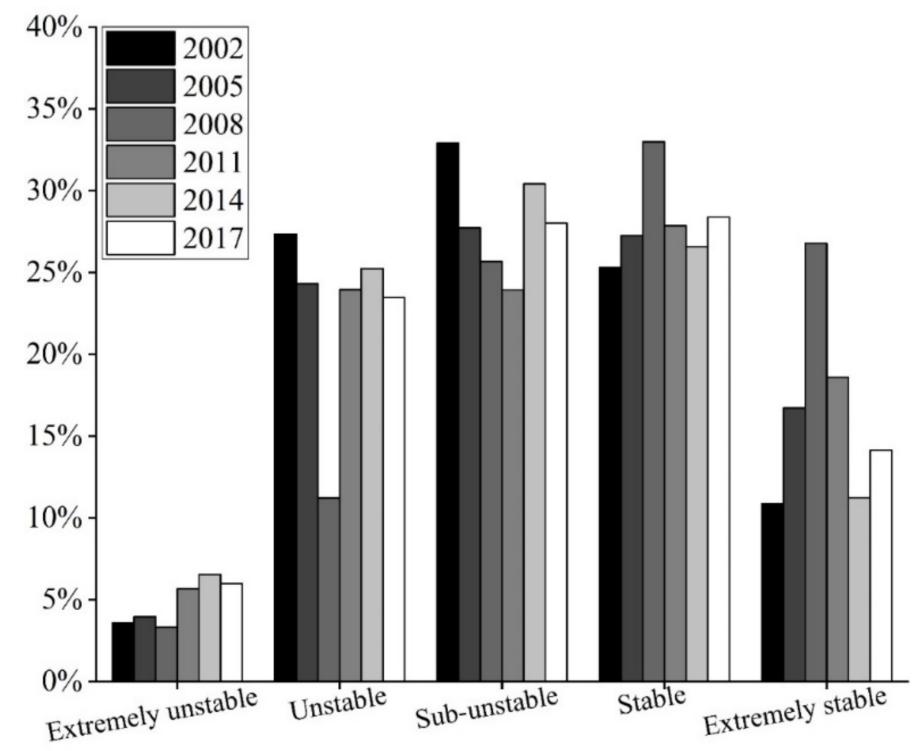

Figure 6. Percentages of different ecological stability grades from 2002 to 2017. 


\subsection{Ecological Structure-Function Interrelation in Coal Mining Area}

Between S-I and S-V states (mining process), the ecological functional comprehensive index of state $\mathrm{S}-\mathrm{V}$, basically below 1.5 , was far lower than that of S-I, showing significant degradation. Moreover, an SDI threshold response (T1) was observed in the west, southwest and east mines, which corresponded to 51.226, 56.486, and 54.116, respectively. This indicated that the mining area ecosystem supported a structural level change of 51 to $56.5 \%$ before a transition from natural to mining state. When S-V transferred to S-IV, the structural thresholds in the transition T2 were, respectively, 83.618, 81.036, and 80.243. In other words, the state altered when the ecological structure of the mining area changed in a good direction by 15 to $20 \%$, from extremely unstable to unstable. At the transition from S-IV to S-III, the structural thresholds in transition T3 were, respectively, 71.521, 67.792, and 72.053. This represented a transfer from unstable to sub-stable when the ecological structure level of S-IV increased by $10-16.5 \%$. The state of S-III supported a $25-30 \%$ change to a good direction in the structural level before crossing a critical threshold to S-II and the structural thresholds in transition T4 were, respectively, 52.277, 47.237, and 50.521. During the above-mentioned state transition processes, overlaps were observed in the variables (structural and functional) of different states.

\subsection{Analysis of Influencing Factors of Ecological Stability}

As for the correlation between ecological stability and elevation, the slope was weak and the correlation coefficients were 0.04 and 0.18 , respectively. Figure 7 illustrates that precipitation was highly and positively correlated with ecological stability $\left(R^{2}=0.9278\right.$, $p<0.05)$. Average temperature and ecological stability were found to be highly and negatively correlated $\left(R^{2}=0.9474, p<0.05\right)$. This context indicated that precipitation and temperature were key factors affecting the ecological stability of the mining area.

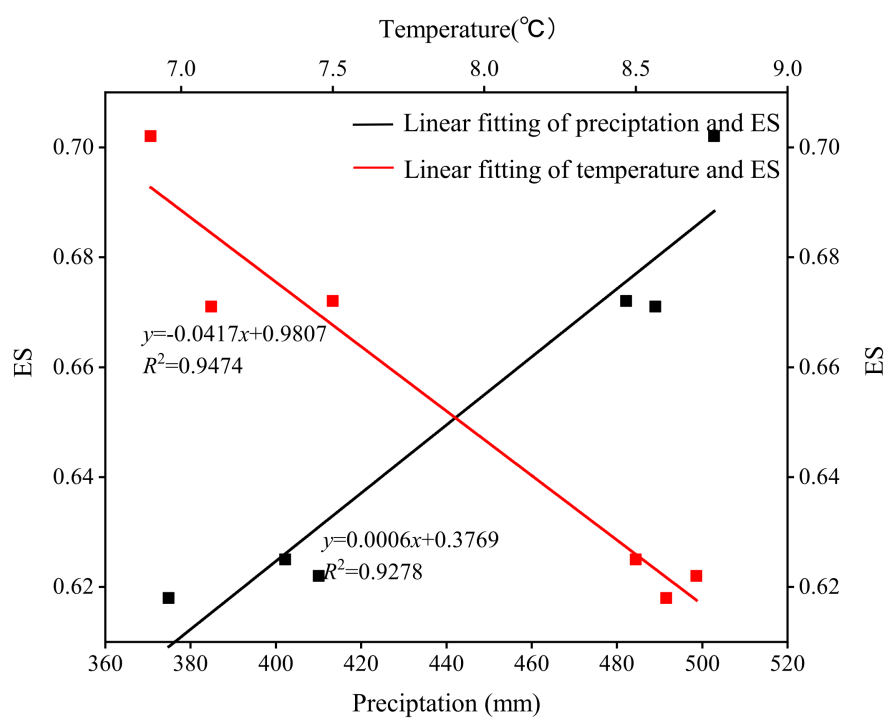

Figure 7. The relationship between ecological stability, precipitation, and temperature.

Figure 8 shows the relationship between ecological stability and distance from coal mining areas in the three mine groups. It was found that the ecological stability of the three mining groups first increased and then decreased with the increase in the distance from the mining area. Based on the function fit results, a function with high fitting accuracy was selected and its first derivative was calculated. The value where the first derivative remained basically unchanged represented the distance at which ecological stability was not affected by mining activities. The average disturbance distances of mining activities on ecological stability in the three mine groups (west, southwest, and east) were 7500, 5500, and $8000 \mathrm{~m}$, respectively. 


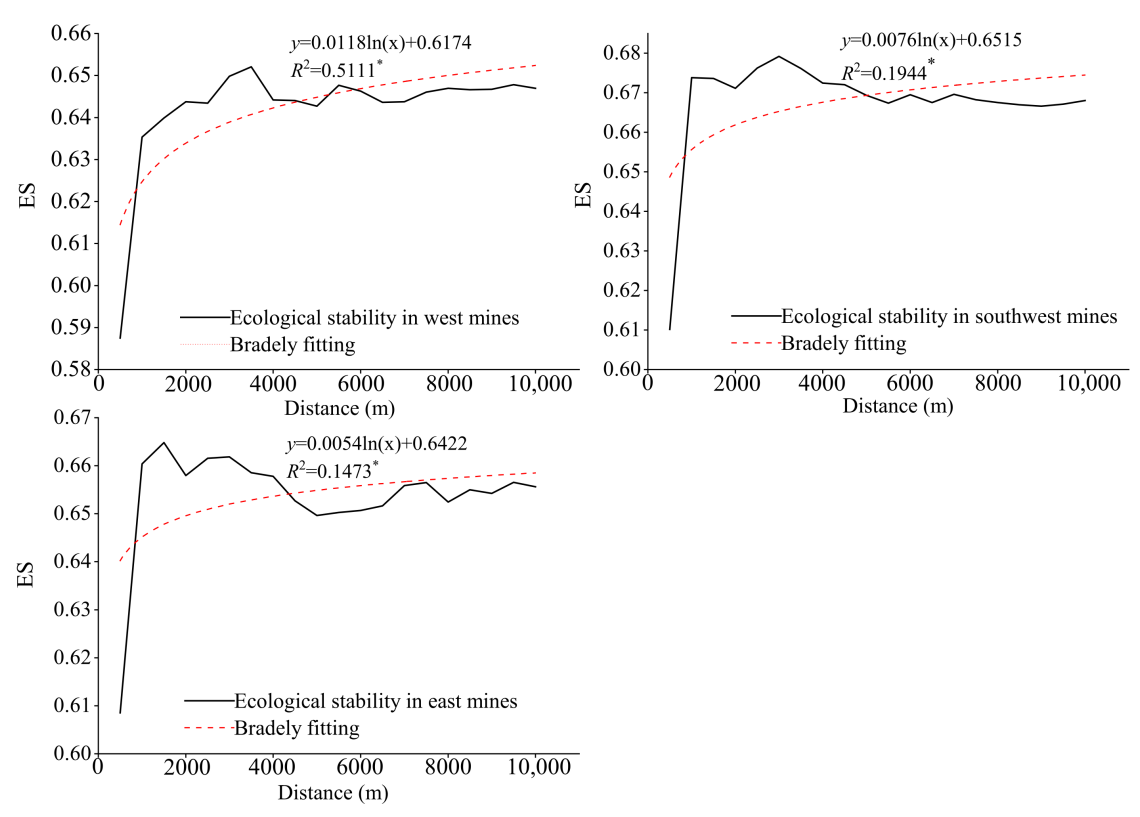

Figure 8. Relationships between ecological stability and distance from coal mining areas in the three mine groups.

It was found that the area in percentage with positive correlations was greater than the area of negative correlations in the Jungar Banner (Figure 9). Positive correlations between NDVI and ecological stability accounted for $40.14,41.60$, and $60.50 \%$ of the total area in the west, southwest, and east coal mine groups, respectively. Among that, the positive correlation areas are mainly distributed around the coal mine areas (Figure 10). In particular, the significant positive correlation areas $(p<0.05)$ were in the coal mine excavation damage areas (e.g., area A) and reclamation areas (e.g., area B). There were significant negative correlations $(p<0.05)$ between NDVI and ecological stability in cultivated areas (e.g., area E) and natural areas in loess hilly regions (e.g., area D). However, a significant positive correlation between NDVI and ecological stability was found in the natural area located in the plain regions (e.g., area C).

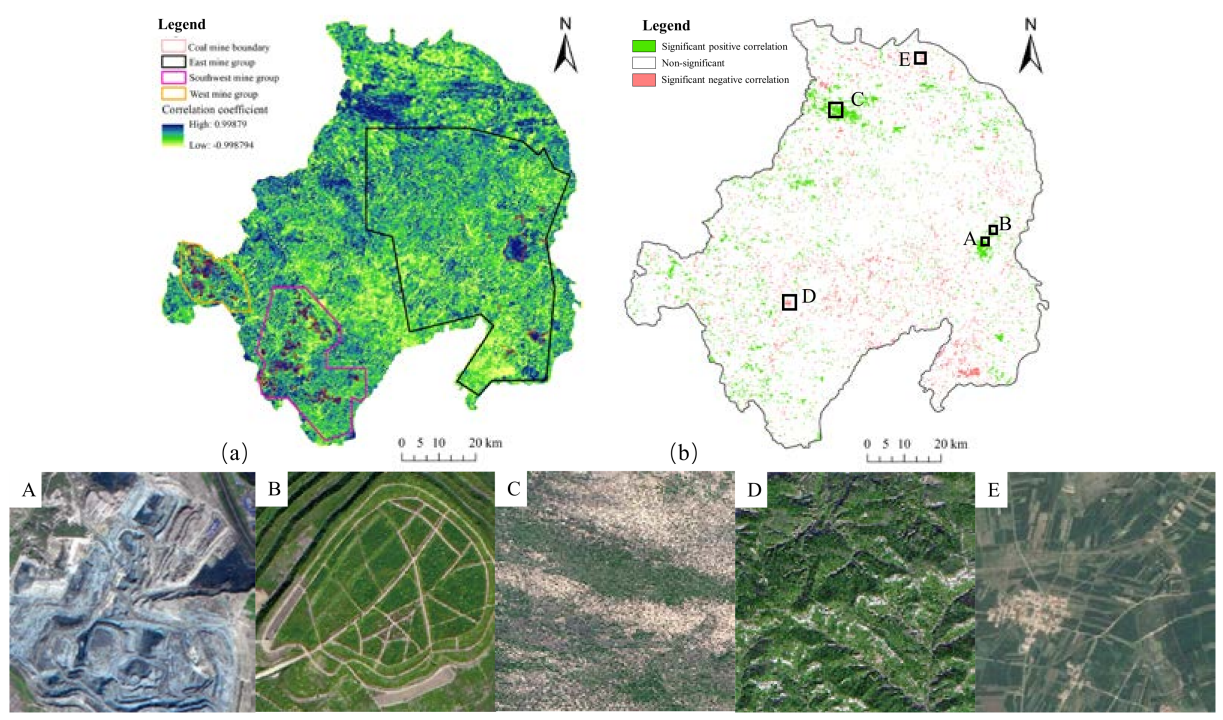

Figure 9. Spatial distribution of correlation (a) and significance (b) between ecological stability of the coal mining area and NDVI in Jungar Banner (A, Coal mine excavation damage area; B, Reclamation area; C, Natural area in the plain region; D, Natural area in loess hilly region; E, Cultivated area). 


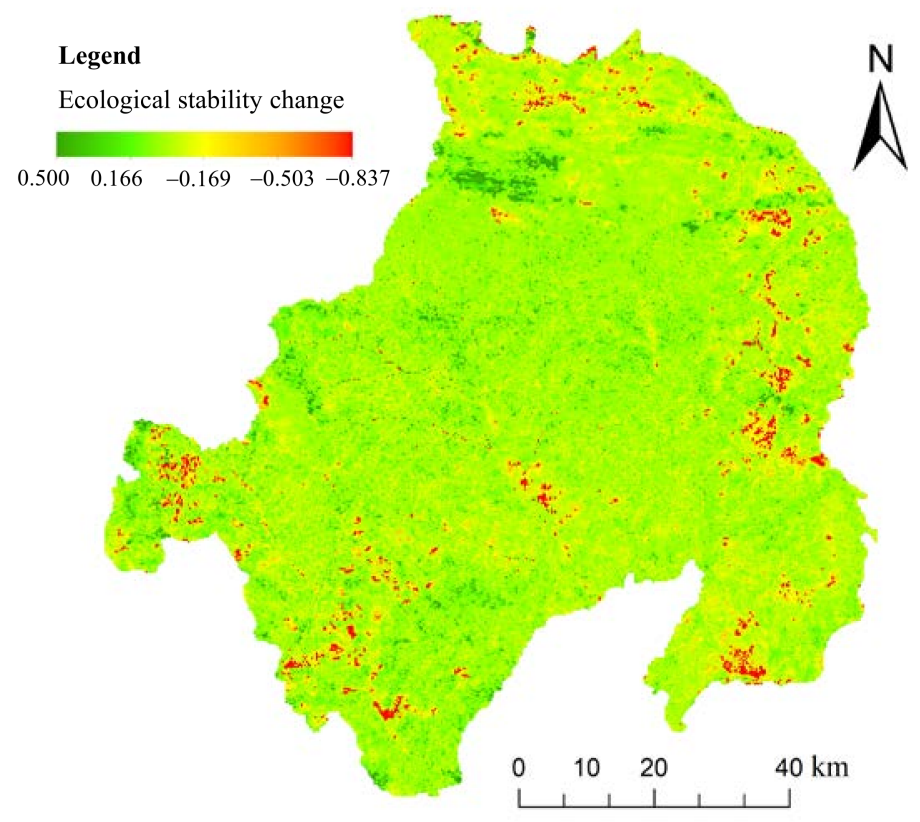

Figure 10. Changes in ecological stability of Jungar Banner between 2002 and 2017 (In the figure, the legend of the ribbon, "+" indicated that the ES was increased, and the ecological environment was better, "-" indicated that the ES was decreased and the ecological environment was worse).

\section{Discussion}

\subsection{The Rationality of Indicators Selection and Evaluation Results}

Hitherto, there are no uniform indicators to evaluate the stability of the ecosystem due to the various description of the ecological stability [43]. Among the existing literature, it is an effective method to choose the evaluation indexes according to the connotation of ecological stability $[44,45]$. Therefore, the selection of ecological stability evaluation indicators is based on the concept of ecological stability in a coal mining area. By obtaining the structural and functional indicators, this study constructs the evaluation model of ecological stability in open-pit coal mine areas, which enriches the research of ecological stability. Different from the thermodynamic entropy method [13], this method can not only analyze the overall changes of ecological stability but also reveal spatial differences.

The selection of structural and functional indicators should be based on the characteristics of the study area [25], meanwhile, they require both scientific and accessibility considerations. Owing to long-term mining disturbances, biological communities have undergone significant changes [46]. The differences in biological communities were mainly concentrated in vegetation removal before mining and vegetation reconstruction after mining, and in the vegetation between the reclaimed and natural areas. This difference can be reflected in terms of vegetation height expressed by the SSI index [37]. Other than vegetation height, mining activities could also affect landscape patterns, which further impacts regional ecological structure and function. The selection of landscape pattern indicators should be confrontational and representative [47]. Studies have shown that with the development of mining activities, landscape fragmentation has increased [48], connections to regional natural landscapes have been broken [49], and the degree of separation has increased. In this way, three landscape pattern indices (SHDI, DIV, and $\mathrm{COH}$ ) were selected to represent ecological structures in the coal mining area. At a regional scale, landscapes generated a wide range of valuable ecosystem services; however, the composition and configuration of landscapes were substantially changed by coal mining activities, which ultimately affected ecological stability. To supplement the shortfall of a static indicator of ecosystem services, herein two indicators including GPP and RUSLE were acquired to reflect the key role played by vegetation systems in ecological activities in the mining area. GPP was expressed as the carbon absorption capacity of vegetation, measuring 
photosynthetic activity [42]. Areas with decreased ecological stability from 2002 to 2017 are mainly concentrated near coal mining areas of west, southwest and east mine groups. The areas where the stability increased by more than 0.16 were mainly located in the north of the study area (Figure 10). Considering the accuracy of ecological stability results, we

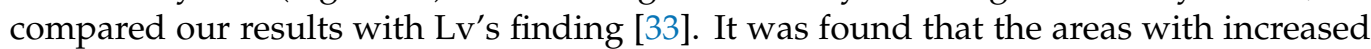
and decreased ecological stability are basically the same as the areas with descending and ascending ecological fragility.

\subsection{Explanation for Spatio-Temporal Changes of Ecological Stability}

Ecosystems in arid and semi-arid regions are vulnerable to climate change. Climate change affects the earth's biological community functions and the provision of ecosystem services [50]. It was exhibited that drought alters the terrestrial carbon cycle and absorption by affecting ecosystem composition, structure, and function [42], thereby impacting GPP. The increase of precipitation in semi-arid mining areas may have promoted vegetation growth [51], thereby inhibiting regional soil erosion. It was found that rising temperature exacerbated drought with a negative impact on vegetation development in mining areas, and increases in temperature adversely impacted carbon exchange, reducing regional GPP [52], and further affecting regional ecological functions and stability. Therefore, precipitation and temperature can both indirectly affect regional ecological stability. Anthropogenic disturbance factors mainly included mining activities and vegetation reconstruction. Mining was the leading factor behind variations in ecological stability. A previous study found that large-scale open-pit mining activities began in the western and southwestern regions of Jungar Banner around 2009 [4], causing vegetation damage, fragmentation of the existing landscape patterns, and continuing to reduce ecological function [9], which explained the phenomenon of the continuous decline in ecological stability in Jungar Banner after 2008. Due to the difference in mining scale and natural geographical conditions, the impact distance of mining on the ecological environment is different. Wu pointed out that the impact distance of open-pit mining on ecological health in grassland mining area is $5 \mathrm{~km}$ [53].

Vidal-Macua et al. [35] and Li et al. [9] reported that after mining, soil conditions became nutrient poor, leading to slower vegetation development and landscape fragmentation, and eventually reducing ecological stability. Moreover, with the increase in the reclamation time, establishing permanent vegetation cover may have restored landscape connectivity and previous ecosystem functions, and improved ecosystem productivity [54] and ecological stability [35]. Therefore, the NDVI for areas A and B were significantly positively correlated with ecological stability $(p<0.05)$. There was less human disturbance in area $C$ and the vegetation community structure was relatively complete. It was located in the plains area with low fragmentation and high ecological function, thus NDVI was positively correlated with ecological stability. A significant negative correlation was found between NDVI and ecological stability in areas D and $\mathrm{E}(p<0.05)$. On the one hand, area D was located in a loess hilly area with fragmented vegetation and severe erosion. On the other hand, it was not that the higher the vegetation coverage, the better the ecological stability. With the increase in the vegetation coverage in the mining area, water and soil were effectively maintained and erosion was prevented [5]. However, the vegetation consumed soil moisture, accompanied by an increase of vegetation transpiration [55]. Jungar Banner is located in a semi-arid area; therefore, excessive water loss resulted in a loss of soil moisture that in turn affected vegetation growth and regional ecological functions. Lu [56] used UAV to extract vegetation information on the dumpsite and found an upper limit of vegetation cover of $45 \%$. Above this value, regional anti-erosion is basically unchanged. Undeniably, a lot more systematic explorations are still demanded to further study optimal vegetation coverage. Cultivated land (E) was severely fragmented and was often subjected to human disturbances, resulting in a decline in farmland production capacity and increased fragmentation of landscape patterns [57], which affected ecological function and resulted in decreased ecological stability. 


\subsection{Structural and Functional Variables under State Transitions}

In an open-pit coal mining ecosystem, positive external forces are required for them to be able to adapt to human disturbance or future climate change, as well as to maintain stability and sustainable development capabilities [3]. Most mining areas have undergone positive ecological construction work focusing on vegetation reconstruction. The results of this study provided concrete evidence of a relationship between improving vegetation structure landscape patterns and improving mining area ecological functions (Figure 11). A transition from one state to another indicated that a threshold of state variables was reached [58], resulting in a shift in ecological structure and function of the coal mining areas [26]. Figure 11 exhibits that it was a slow process to recover from state $S-V$ to state $\mathrm{S}$-II, and ecological structure and function were gradually developing toward a positive state. In the mining area, the occurrence of structural thresholds was mainly due to the following reasons: vegetation restoration caused changes in landscape patches, reducing the degree of ecosystem fragmentation and increasing the degree of landscape aggregation; and the function threshold was associated with key ecological activities, such as soil erosion and carbon absorption capacity. In general, there were overlaps in ecological structure and function attributes in different ecological stability states. In the transition from S-V to S-II state, when an external force was applied (vegetation construction), the structural and functional values of partial samples from state S-II were close to or even exceeded for some samples belonging to state S-I. This was due to the extension of the reclamation period, during which soil environmental factors gradually improved and were close to the natural control area. Under the interacting influence of soil and vegetation, the vegetation community developed a rich and stable structure [59] that reduced soil loss caused by erosion and increased the carbon cycle to further improve regional ecological functions [60].
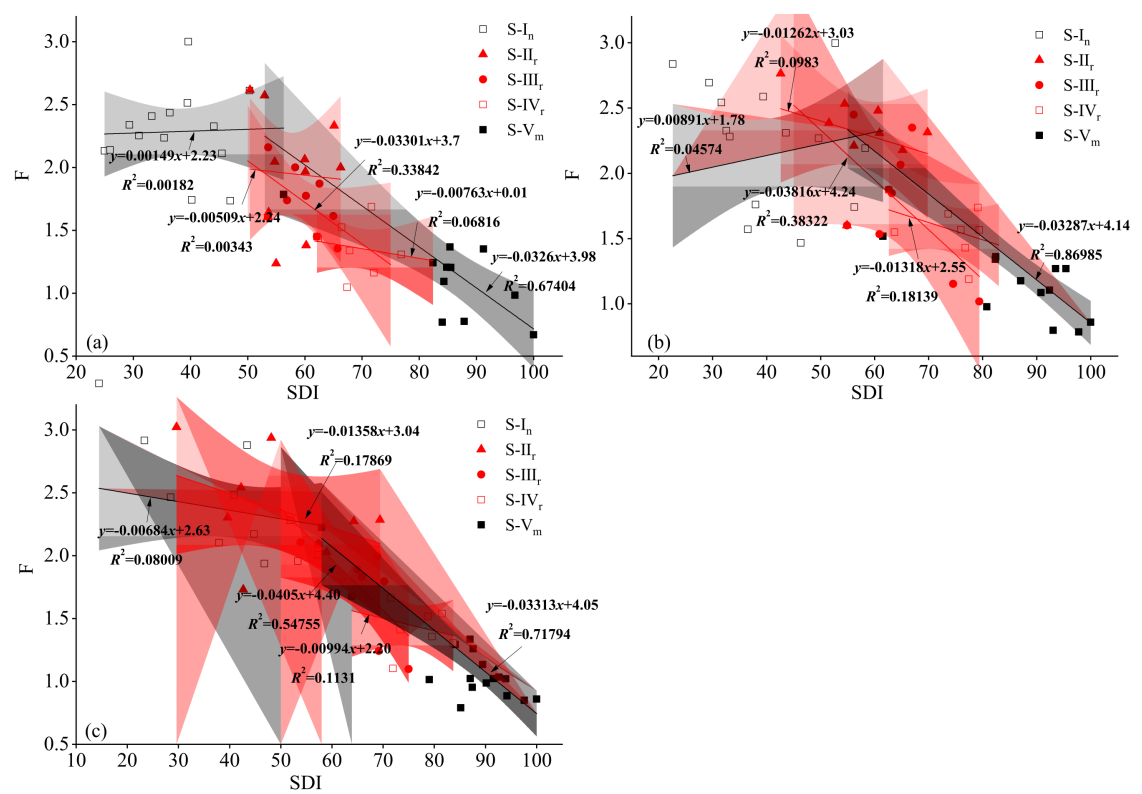

Figure 11. SFSTM approach for coal mining areas in Jungar Banner. Segmented regressions were adjusted between the structural degradation index (SDI explaining the $x$ axis) $[2,26]$ and the response variable ecosystem functional comprehensive index (F) (y axis). ((a), (b), (c) represent the west, southwest, and east coal mines, respectively).

The SFSTM model reduced ecosystem uncertainty, avoided reverse conversions when the state was required to be preserved in higher ecological stability, and degraded the system to a lower-level state. The SFSTM model was used to identify deviated states, which required proper management to lead them to the ideal path. Therefore, the following suggestions were made for the transition between different states of mining area ecosystems: 
(1) Acceleration of state transitions. Before the positive restoration threshold is reached, soil fertilization can be carried out to facilitate the nutrient environment required for later vegetation growth. Soil quality is a basic element that determines vegetation restoration; (2) Avoidance of reverse vegetation conversion. After a positive restoration threshold is reached, later management and protection should be regularly strengthened [3], which is an important guarantee for vegetation restoration.

\subsection{Partition for Ecological Stability Improvements and Management}

According to the geomorphic types, the three coal mine areas (A, B, C) in Jungar Banner (Figure 2) were divided into the following ecological management areas: coarse-soil aeolian sand in the west, loess hills in the southwest, and low hills and loess in the east. Undeniably, vegetation restoration was the focus of ecological stability improvement and management in the partition management. Studies found that the main methods for vegetation restoration in mining areas are seedling planting, direct seeding, natural restoration (natural regeneration), and seedling transplantation [61]. Seedling transplantation, the most common method, possesses the advantage of using different types of species combinations and the most suitable soil for local environmental conditions to implement vegetation reconstruction [62]. Field investigations showed that the most common combination of reclaimed vegetation in the dumps of the Jungar Banner mining area was Medicago sativa L., Melilotus officinalis (L.) Pall., and Astragalus adsurgens Pall [9]. However, the stability of the dumping site under different vegetation allocations has rarely been investigated, which is a key issue for future research.

Moreover, source control and soil remediation were clearly warranted for ecological stability improvement and management. Figure 8 shows that the influence of mining activities on area $\mathrm{A}$ was greater than that on area B. When the mining scale and intensity were basically the same, the main reason was that the soil in the west coal mining area was thin humus with poor fertility, thus ecological stability improvement and management suggestions for area A aimed to strengthen soil management and increase fertilization. Considering that the mining activities were dispersed in area B, it increased not only the fragmentation of the regional landscape, but also the difficulty of reclamation. Therefore, it was suggested to strictly control the expansion of construction and mining land and merge adjacent dumps to exploit. Area $C$ was adjacent to the Yellow River and was accompanied by high intensity and large-scale mining, thus, the first step for ecological stability improvement and management should strengthen water resources protection and improve water use efficiency. Furthermore, integrating new technologies and concurrent mining and reclamation could shorten mining hours and reduce pollution.

\section{Conclusions}

It is necessary to study the ecological stability of coal mining areas by coupling structural and functional variables related to mining ecosystems and reclamation practices. The average ecological stability of Jungar Banner showed a fluctuating trend, first increasing and then decreasing. The extremely unstable and unstable areas were mainly distributed around open-pit coal mines and towns. Ecological stability was a result of human factors (coal mining, vegetation reconstruction) and natural factors (precipitation, temperature, elevation, and slope). Of these, mining activities were the dominant factor influencing variation in ecological stability. There were significant positive correlations between NDVI and ecological stability in the coal mine excavation damage areas and reclamation areas. Precipitation was positively correlated with ecological stability, and temperature was negatively correlated. Based on the structural and functional state transition model, in this study, structural change thresholds were determined for negative state transitions due to mining (e.g., S-I to S-V, the altered state when the ecological structure of S-I changed from 51 to $56.5 \%$ ) and positive state transitions due to reclamation (e.g., S-V to S-II, recovery was a slow process). Furthermore, we provided suggestions for ecological stability improvement and management in different coal mine groups in Jungar Banner to ensure 
sustainable development of the regional ecosystem. The advantage of this method includes the accessibility of variables, which can be applied to a larger range of coal mining areas.

Author Contributions: Conceptualization, X.L. (Xinhui Li); Investigation, Y.Z.; Methodology, X.L. (Xinhui Li); Project administration, Z.B.; Resources, C.G.; Software, H.C. and X.L. (Xiaoguang Lu); Supervision, S.L.; Validation, Y.Z.; Visualization, H.C.; Writing-original draft, X.L. (Xinhui Li); Writing-review \& editing, Y.L. All authors have read and agreed to the published version of the manuscript.

Funding: This work was supported by the Future Scientists Program of China University of Mining and Technology (No. 2020WLKXJ050) and the Postgraduate Research \& Practice Innovation Program of Jiangsu Province (No. KYCX20_2032).

Data Availability Statement: The data used in this study (except the boundary of mineral resources) are openly available on the websites. The boundary of mineral resources are available from the Environmental Restoration and Management Center of the Jungar Banner mining area.

Acknowledgments: We would like to thank Feng Liu and Weizhong Wang in the Environmental Restoration and Management Center of the Jungar Banner mining area for their help in the available of data collection. The authors greatly appreciatethe editors and anonymous reviewers for their positive comments on the manuscript.

Conflicts of Interest: The authors declare no conflict of interest.

\section{References}

1. Yuan, Y.; Zhao, Z.; Niu, S.; Li, X.; Wang, Y.; Bai, Z. Reclamation promotes the succession of the soil and vegetation in opencast coal mine: A case study from Robinia pseudoacacia reclaimed forests, Pingshuo mine, China. Catena 2018, 165, 72-79. [CrossRef]

2. López, D.R.; Brizuela, M.A.; Willems, P.; Aguiar, M.R.; Siffredi, G.; Bran, D. Linking ecosystem resistance, resilience, and stability in steppes of North Patagonia. Ecol. Indic. 2013, 24, 1-11. [CrossRef]

3. Bian, Z.F.; Lei, S.G.; Jin, D.; Wang, L. Several basic scientific issues related to mined land remediation. J. China Coal Soc. 2018, 43, 190-197.

4. Li, X.; Lei, S.; Cheng, W.; Liu, F.; Wang, W. Spatio-temporal dynamics of vegetation in Jungar Banner of China during 2000-2017. J. Arid Land. 2019, 11, 837-854. [CrossRef]

5. Gong, C.; Lei, S.; Bian, Z.; Liu, Y.; Zhang, Z.; Cheng, W. Analysis of the Development of an Erosion Gully in an Open-Pit Coal Mine Dump during a Winter Freeze-Thaw Cycle by Using Low-Cost UAVs. Remote Sens. 2019, 11, 1356. [CrossRef]

6. Ying, L.; Shaogang, L.; Xiaoyang, C. Assessment of heavy metal pollution and human health risk in urban soils of a coal mining city in East China. Hum. Ecol. Risk Assess. An. Int. J. 2016, 22, 1359-1374. [CrossRef]

7. Dong, S.; Samsonov, S.; Yin, H.; Yao, S.; Xu, C.; Song, Y.; Sun, Y.; Lei, K.; Kolditz, O.; Liu, R.; et al. Spatio-temporal analysis of ground subsidence due to underground coal mining in Huainan coalfield, China. Environ. Earth Sci. 2015, 73, 5523-5534. [CrossRef]

8. MacArthur, R. Fluctuations of Animal Populations and a Measure of Community Stability. Ecology 1955, 36, 533-536. [CrossRef]

9. Li, X.; Lei, S.; Liu, F.; Wang, W. Analysis of Plant and Soil Restoration Process and Degree of Refuse Dumps in Open-Pit Coal Mining Areas. Int. J. Environ. Res. Public Health 2020, 17, 1975. [CrossRef] [PubMed]

10. López, D.R.; Cavallero, L.; Brizuela, M.A.; Aguiar, M.R. Ecosystemic structural-functional approach of the state and transition model. Appl. Veg. Sci. 2011, 14, 6-16. [CrossRef]

11. May, M.R. Will a large complex system be stable? Nature 1972, 238, 413-414. [CrossRef]

12. Harrison, G.W. Stability under environmental stress: Resistance, resilience, persistence, and variability. Am. Nat. 1979, 113, 659-669. [CrossRef]

13. Yue, T.X.; Ma, S.J. Eosystem stability and its analysing model. Acta Ecol. Sin. 1991, 4, 361-366.

14. Vefue, L. The Penguin Directionary of Physics; Foreign Language Press: Beijing, China, 1996.

15. Yang, S. Urban Ecology; Science Press: Beijing, China, 2003.

16. Yuan, J.; Bian, Z.; Yan, Q.; Pan, Y. Spatio-Temporal Distributions of the Land Use Efficiency Coupling Coordination Degree in Mining Cities of Western China. Sustainability 2019, 11, 5288. [CrossRef]

17. Westoby, M.; Brian, W.; Imanuel, N.M. Opportunistic management for rangelands not at equilibrium. J. Rangel. Manag. 1989, 42, 266-274. [CrossRef]

18. Briske, D.D.; Smeins, S. Vegetation dynamics on rangelands: A critique of the current paradigms. J. Appl. Ecol. 2003, 40, 601-614. [CrossRef]

19. Briske, D.D.; Fuhlendorf, S.D.; Smeins, F.E. State-and-Transition Models, Thresholds, and Rangeland Health: A Synthesis of Ecological Concepts and Perspectives. Rangel. Ecol. Manag. 2005, 58, 1-10. [CrossRef]

20. Briske, D.D.; Bestelmeyer, B.T.; Stringham, T.K.; Shaver, P.L. Recommendations for Development of Resilience-Based State-andTransition Models. Rangel. Ecol. Manag. 2008, 61, 359-367. [CrossRef] 
21. Bestelmeyer, B.T.; Tugel, A.J.; Peacock, G.L.; Robinett, D.G.; Shaver, P.L.; Brown, J.R.; Herrick, J.E.; Sanchez, H.; Havstad, K.M. State-and-Transition Models for Heterogeneous Landscapes: A Strategy for Development and Application. Rangel. Ecol. Manag. 2009, 62, 1-15. [CrossRef]

22. Bagchi, S.; Briske, D.D.; Bestelmeyer, B.T.; Wu, X.B. Assessing resilience and state-transition models with historical records of cheatgrass Bromus tectorum invasion in North American sagebrush-steppe. J. Appl. Ecol. 2013, 50, 1131-1141. [CrossRef]

23. Young, D.; Perotto-Baldivieso, H.L.; Brewer, T.; Homer, R.; Santos, S.A. Monitoring british upland ecosystems with the use of landscape structure as an indicator for state-and-transition models. Rangel. Ecol. Manag. 2014, 67, 380-388. [CrossRef]

24. Hein, L. The impacts of grazing and rainfall variability on the dynamics of a Sahelian rangeland. J. Arid Environ. 2006, 64, 488-504. [CrossRef]

25. Cavallero, L.; López, D.R.; Raffaele, E.; Aizen, M.A. Structural-functional approach to identify post-disturbance recovery indicators in forests from northwestern Patagonia: A tool to prevent state transitions. Ecol. Indic. 2015, 52, 85-95. [CrossRef]

26. Peri, P.L.; López, D.R.; Rusch, V.; Rusch, G.; Rosas, Y.M.; Martínez Pastur, G. State and transition model approach in native forests of Southern Patagonia (Argentina): Linking ecosystem services, thresholds and resilience. Int. J. Biodivers. Sci. Ecosyst. Serv. Manag. 2017, 13, 105-118. [CrossRef]

27. Li, N.; Yan, C.Z.; Xie, J.L. Remote sensing monitoring recent rapid increase of coal mining activity of an important energy base in northern China, a case study of Mu Us Sandy Land. Resour. Conserv. Recycl. 2015, 94, 129-135. [CrossRef]

28. Zhang, M.; Wang, J.; Li, S.; Feng, D.; Cao, E. Dynamic changes in landscape pattern in a large-scale opencast coal mine area from 1986 to 2015: A complex network approach. Catena 2020, 194, 104738. [CrossRef]

29. Wang, Y.C.; Bian, Z.F.; Lei, S.; Zhang, Y. Investigating spatial and temporal variations of soil moisture content in an arid mining area using an improved thermal inertia model. J. Arid Land. 2017, 9, 712-726. [CrossRef]

30. Yang, Z.; Li, W.; Li, X.; He, J. Quantitative analysis of the relationship between vegetation and groundwater buried depth: A case study of a coal mine district in Western China. Ecol. Indic. 2019, 102, 770-782. [CrossRef]

31. Bao, N.; Wu, L.; Liu, S.; Li, N. Scale parameter optimization through high-resolution imagery to support mine rehabilitated vegetation classification. Ecol. Eng. 2016, 97, 130-137. [CrossRef]

32. Wu, Z.; Lei, S.; He, B.; Bian, Z.; Wang, Y.; Lu, Q.; Peng, S.; Duo, L. Assessment of Landscape Ecological Health: A CaseStudy of a Mining City in a Semi-Arid Steppe. Int. J. Environ. Res. Public Health 2019, 16, 752. [CrossRef] [PubMed]

33. Lv, X.; Xiao, W.; Zhao, Y.; Zhang, W.; Li, S.; Sun, H. Drivers of spatio-temporal ecological vulnerability in an arid, coal mining region in Western China. Ecol. Indic. 2019, 106, 105475. [CrossRef]

34. Kandziora, M.; Burkhard, B.; Müller, F. Interactions of ecosystem properties, ecosystem integrity and ecosystem service indicatorsA theoretical matrix exercise. Ecol. Indic. 2013, 28, 54-78. [CrossRef]

35. Vidal-Macua, J.J.; Nicolau, J.M.; Vicente, E.; Moreno-de Las Heras, M. Assessing vegetation recovery in reclaimed opencast mines of the Teruel coalfield (Spain) using Landsat time series and boosted regression trees. Sci. Total Environ. 2020, 717, 137250. [CrossRef]

36. Jiao, Z.; Li, X.; Wang, J.; Zhang, H. Assessment of MODIS BRDF shape indicators. J. Remote Sens. 2011, 15, 432-456.

37. Yang, Y.J. Study on the Resilience of Land Ecosystem in Mining Area and Its Measurement and Regulation; China University of Mining and Technology: Xuzhou, China, 2017.

38. Xie, G.D.; Zhang, Y.L.; Lu, C.X. Study on valuation of rangeland ecosystem services of China. J. Nat. Resour. $2001,16,47-53$.

39. Lei, J.; Chen, Z.Z.; Wu, T.T.; Li, Y.L.; Yang, Q.; Chen, X.H. Spatial autocorrelation pattern analysis of land use and the value of ecosystem services in northeast Hainan island. Acta Ecol. Sin. 2019, 39, 2366-2377.

40. Zhuang, H.; Wang, Y.; Liu, H.; Wang, S.; Zhang, W.; Zhang, S.; Dai, Q. Large-Scale Soil Erosion Estimation Considering Vegetation Growth Cycle. Land 2021, 10, 473. [CrossRef]

41. Yang, Y.; Li, Y.; Chen, F.; Zhang, S.; Hou, H. Regime shift and redevelopment of a mining area's socio-ecological system under resilience thinking: A case study in Shanxi Province, China. Environ. Dev. Sustain. A Multidiscip. Approach Theory Pract. Sustain. Dev. 2018, 21, 2577-2598. [CrossRef]

42. Du, L.; Mikle, N.; Zou, Z.; Huang, Y.; Shi, Z.; Jiang, L.; McCarthy, H.R.; Liang, J.; Luo, Y. Global patterns of extreme droughtinduced loss in land primary production: Identifying ecological extremes from rain-use efficiency. Sci. Total Environ. 2018, 628-629, 611-620. [CrossRef]

43. Ma, F. Research Advances on Ecosystem Stability. J. Desert Res. 2002, 22, 401-407.

44. Wu, Z.; Lei, S.; Lu, Q.; Bian, Z. Impacts of Large-Scale Open-Pit Coal Base on the Landscape Ecological Health of Semi-Arid Grasslands. Remote Sens. 2019, 11, 1820. [CrossRef]

45. Gao, X.; Huang, P.T.; Wang, K. Assessment of the ecosystem stability of Shapotou Arid Desert Nature Reserve in Ningxia, China. Acta Ecol. Sin. 2019, 39, 6381-6392.

46. Zhang, Z.; Wang, J.; Feng, Y. Linking the reclaimed soils and rehabilitated vegetation in an opencast coal mining area: A complex network approach. Environ. Sci. Pollut. Res. 2019, 26, 19365-19378. [CrossRef] [PubMed]

47. Fang, A.; Bao, M.; Chen, W.; Dong, J. Assessment of Surface Ecological Quality of Grassland Mining Area and Identification of Its Impact Range. Nat. Resour. Res. 2021, 30, 3819-3837. [CrossRef]

48. Hendrychová, M.; Kabrna, M. An analysis of 200-year-long changes in a landscape affected by large-scale surface coal mining: History, present and future. Appl. Geogr. 2016, 74, 151-159. [CrossRef] 
49. Xu, W.; Wang, J.; Zhang, M.; Li, S. Construction of landscape ecological network based on landscape ecological risk assessment in a large-scale opencast coal mine area. J. Clean. Prod. 2021, 286, 125523. [CrossRef]

50. Barbosa, J.M.; Asner, G.P. Effects of long-term rainfall decline on the structure and functioning of Hawaiian forests. Environ. Res. Lett. 2016, 12, 94002. [CrossRef]

51. Ma, Q.; Liu, X.; Li, Y.; Li, L.; Yu, H.; Qi, M.; Zhou, G.; Xu, Z. Nitrogen deposition magnifies the sensitivity of desert steppe plant communities to large changes in precipitation. J. Ecol. 2020, 108, 598-610. [CrossRef]

52. Dai, A. Drought under global warming: A review. Wiley Interdiscip. Rev. Clim. Chang. 2010, 2, 45-65. [CrossRef]

53. Wu, Z.; Lei, S.; Lu, Q.; Bian, Z.; Ge, S. Spatial distribution of the impact of surface mining on the landscape ecological health of semi-arid grasslands. Ecol. Indic. 2020, 111, 105996. [CrossRef]

54. Fan, X.; Song, Y.; Zhu, C.; Balzter, H.; Bai, Z. Estimating Ecological Responses to Climatic Variability on Reclaimed and Unmined Lands Using Enhanced Vegetation Index. Remote Sens. 2021, 13, 1100. [CrossRef]

55. Liu, Y.; Lei, S.G.; Gong, C.G.; Bian, Z.F. Effects of soil water content change on the chlorophyll fluorescence response of Caragana korshinskii leaves under the influence of coal mining subsidence cracks. Acta Ecol. Sin. 2019, 39, 3267-3276.

56. Lu, J. Monitoring of Vegetation and Soil Erosion in Dump Slope Based on UAV Remote Sensing Technology; China University of Mining and Technology: Xuzhou, China, 2018.

57. Xu, W.; Jin, X.; Liu, J.; Zhou, Y. Analysis of influencing factors of cultivated land fragmentation based on hierarchical linear model: A case study of Jiangsu Province, China. Land Use Policy 2020, 101, 105119. [CrossRef]

58. Bestelmeyer, B.T.; Williamson, J.C.; Talbot, C.J.; Cates, G.W.; Duniway, M.C.; Brown, J.R. Improving the Effectiveness of Ecological Site Descriptions: General State-and-Transition Models and the Ecosystem Dynamics Interpretive Tool (EDIT). Rangelands 2016, 38, 329-335. [CrossRef]

59. Wang, J.M.; Guo, L.L.; Bai, Z.K.; Yang, R.X.; Zhang, M. Succession law of reclaimed soil and vegetation on opencast coal mine dump of loess area. Trans. Chin. Soc. Agric. Eng. 2013, 29, 223-232.

60. Ludwig, J.A.; Tongway, D.J.; Bastin, G.N.; James, C.D. Monitoring ecological indicators of rangeland functional integrity and their relation to biodiversity at local to regional scales. Austral. Ecol. 2004, 29, 108-120. [CrossRef]

61. Bruno Rocha Martins, W.; Douglas Roque Lima, M.; de Oliveira Barros Junior, U.; Sousa Villas-Boas Amorim, L.; de Assis Oliveira, F.; Schwartz, G. Ecological methods and indicators for recovering and monitoring ecosystems after mining: A global literature review. Ecol. Eng. 2020, 145, 105707. [CrossRef]

62. Villacís, J.; Armas, C.; Hang, S.; Casanoves, F. Selection of Adequate Species for Degraded Areas by Oil-Exploitation Industry as a Key Factor for Recovery Forest in the Ecuadorian Amazon. Land Degrad. Dev. 2016, 27, 1771-1780. [CrossRef] 